\title{
EDITORIAL
}

\section{LA ASAMBLEA DE FUNDADORES DE LA U.D.C.A}

Germán Anzola Montero

Rector

¿Por qué es significativa la Asamblea de Fundadores de la U.D.C.A? Inicio este Editorial para la Revista Científica con esta pregunta, con el propósito que todos entendamos las funciones y las obligaciones de nuestros Miembros Fundadores. Vale la pena traer a la memoria, que hace más de 25 años, se unieron distinguidos personajes, profesionales de diversas áreas del conocimiento, para instituir un proyecto educativo, al que asignaron el nombre Corporación Universitaria de Ciencias Agropecuarias. Sin duda alguna, sus 13 fundadores, visionaron este proyecto, el cual, actualmente, reúne un substancial número de estudiantes, tanto de pregrado como de postgrado, docentes de alta especialidad y administrativos calificados, en las diferentes áreas y dependencias de la Institución.

Es menester de la Asamblea estar comprometido con este quehacer y de avalar las innumerables propuestas, todas a favor del bienestar y la calidad de la Universidad, tanto en el ámbito académico como en el administrativo. Año tras año, la Rectoría entrega un informe detallado de lo ejecutado en el último periodo y los nuevos proyectos y planes, para el siguiente.

Este año, a sus Fundadores, se les notificó que en el periodo 2008 - 2009, la Universidad continuó empeñada en buscar nuevas maneras y estrategias para alcanzar indicadores de excelencia en nuestro quehacer universitario y para lograrlo, la Rectoría siguió orientando, tanto la nómina de directivos, de personal académico, de funcionarios y de estudiantes, con criterios de innovación y de permanente cambio, con miras a ofrecer una función educativa en lo superior, equivalente a la oferta que brindan a la sociedad, las instituciones de educación superior más desarrolladas del país.

Consecuente con ello, la Rectoría compartió los planes y los proyectos que hemos de trabajar en este nuevo lapso académico, que inició en el mes de marzo de 2009. Tales acciones representan nuestra respuesta a las necesidades expresas de la Universidad del siglo XXI y que comprenden la incorporación de renovadas propuestas, para cumplir el quehacer docente, investigativo y de extensión.

En cumplimiento con estos planes, que confiamos en hacerlos realidad y, específicamente, en el presente año, son los de obtener los registros calificados, por lo menos, para tres programas de Maestría de Investigación, logro que sólo será posible, en la medida que las iniciativas y las orientaciones de la Rectoría, se complementen con la consolidación de los grupos de investigación, afines al objeto de estudio de las Maestrías, sometidas a consideración del MEN, reto que debe recibir todo el apoyo por parte de las Vicerrectorías Académica y de Investigaciones. La propuesta Maestrías de Investigación es el sendero para conseguir, en tres años, la acreditación institucional y lograr el inicio de programas de Doctorado.

Nuestro objetivo, en materia de cobertura, no solo debe ser a nivel de los programas de pregrado sino también de postgrados, fundamentado en las realidades de la oferta y la demanda, generado por el ingreso a estudios de educación superior.

Otro proyecto en curso y que compromete a todos los cuerpos colegiados de la U.D.C.A, es el de implementación y de manejo de las TIC, soporte esencial de una universidad moderna, en el cumplimiento de sus funciones sustantivas y en su óptima y adecuada administración.

Todos los anteriores son hechos que reafirman mi compromiso, en primera instancia, como Rector y de todos los funcionarios de la Universidad, con la Asamblea de Fundadores. 
El presente y el futuro de la U.D.C.A, en nuestras manos, me permiten recordar, cuando hace 23 años, inspirado en mi condición de educador, de docenteinvestigador universitario, en el conocimiento de la universidad colombiana, pero sobre todas las quimeras, en los requerimientos de jóvenes hombres y mujeres, colombianos ellos, que requieren de una educación superior asequible a sus condiciones sociales y económicas y convencido, sin tipo de impedimento y barrera, de la inmensa felicidad sentida por el servicio que se puede prestar a los demás, imaginé una UNIVERSIDAD y no otro ideal. Es así, como con el apoyo del Consejo Directivo y acompañado de un significativo número de universitarios y universitarias, empezamos a construir un proyecto educativo, hoy llamado UNIVERSIDAD DE CIENCIAS APLICADAS Y AMBIENTALES U.D.C.A.

Afrontando con decisión las dificultades, siempre de orden económico-financiero y las propias del quehacer universitario, nos hemos unido, a hoy, un sinnúmero de personas convencidas que, en ellos, académicos y académicas, tenemos el mejor recurso y talento para perseverar con este proyecto educativo.

Los cinco lustros de labor, en continua mejora y perfeccionamiento de nuestra misión académica, venciendo dificultades, aprendiendo día a día, gestando innovación, con visión firme frente a las exigencias del conocimiento y experiencia académica es lo que nos permiten creer en 25 años más, de nuestra Universidad $\mathrm{y}$, con ello, es que superamos las limitaciones de orden financiero.

Como la Rectoría lo indicó a sus miembros Fundadores, se inició el proyecto UNIVERSIDAD PARA EL SIGLO XXI, que contempla el fortaleciendo de todos aquellos procesos que favorezcan la generación del conocimiento en las diferentes áreas de trabajo, pues este nuevo conocimiento, es el que puede lograr los cambios conducentes a la revolución científica y tecnológica, que requiere y exige el país. En esta ocasión debo

${ }^{1}$ Consejo Nacional de Acreditación. 2009. Disponible desde Internet en: www.cna.gov.co (con acceso 23/02/09). ratificarme, con pleno y total convencimiento, para que la U.D.C.A dirija todos sus esfuerzos investigativos a favor y búsqueda de solución a nuestros problemas y en beneficio del desarrollo oportuno, favorable y efectivo en lo social y económico, específicamente, de la sociedad colombiana.

El informe dirigido a la Asamblea de Fundadores, lo concluí proponiéndoles hacer, como propio de nuestro PEI, lo consignado en el reciente informe del Consejo Nacional de Acreditación, en un documento titulado Lineamientos para la Acreditación de Alta Calidad de Maestrías y Doctorados ${ }^{1}$, y que haciendo referencia a la Universidad de hoy al concepto de Universidad Plena, señala: "En primer lugar, el espectacular avance que se ha logrado en algunos campos del conocimiento (v.gr. biología molecular, nuevos materiales, informática, etc.) ha acortado dramáticamente la distancia entre el laboratorio y la línea de producción. Anteriormente había un "ciclo de gestación de aplicaciones del conocimiento" de 15 a 50 años que separaba la investigación básica que se realizaba en los laboratorios de sus posibles aplicaciones en el sector productivo o en la comunidad, ya sea como un nuevo producto (final o intermedio), proceso de producción o servicio. Actualmente dichos ciclos se han acortado a dos o tres años en algunos casos, debido al hecho que los resultados y productos de la investigación en laboratorios científicos muy rápidamente encuentran aplicaciones de diversa índole en el sector productivo, o en la solución de problemas sociales o ambientales en su entorno. La distinción clásica entre investigación básica, investigación aplicada y desarrollo tecnológico se desdibuja y evoluciona hacia procesos interactivos o espirales virtuosas de generación y uso de conocimiento que enriquece este último.

En segundo lugar, el impacto del progreso científico se ha visto potenciado por otra característica importante que tiene la Sociedad o Economía del Conocimiento. Se está pasando la era de sistemas de producción basados eminentemente en recursos físicos y energéticos, a sistemas de producción basados en el conocimiento, o cuya eficiencia y productividad dependen de su capacidad de generación y uso del conocimiento. Este último, se ha convertido en un factor de producción 
que desempeña un papel fundamental en la solución de problemas sociales y ambientales.

En tercer lugar, los problemas de desarrollo social y de sostenibilidad de nuestra sociedad y su entorno se han incrementado, a pesar del avance notable de la ciencia y la tecnología y de la creciente capacidad para solucionar problemas que ello genera. Los desafíos que hoy se confrontan en términos de sostenibilidad económica (generación de empleo), sostenibilidad social (asegurar un desarrollo con inclusión social) y sostenibilidad ambiental (manejo sostenible de la biodiversidad y del medio ambiente) generan la necesidad ineludible de crear conocimiento que sea relevante para la solución de tales problemas, buscando aplicarlo en forma innovadora a su solución...". 